\title{
Plasma 8-hydroxy-2'-deoxyguanosine Levels in Huntington Disease and Healthy Controls Treated with Coenzyme Q10
}

\author{
K.M. Biglan ${ }^{a, *}$, E.R. Dorsey ${ }^{\mathrm{a}, \mathrm{b}}$, R.V.V. Evans ${ }^{\mathrm{a}}$, C.A. Ross ${ }^{\mathrm{c}}$, S. $\operatorname{Hersch}^{\mathrm{d}}$, I. Shoulson ${ }^{\mathrm{a}, \mathrm{e}}$, W. Matson ${ }^{\mathrm{f}}$ \\ and K. Kieburtz ${ }^{\text {a }}$ for the Huntington Study Group Pre-2CARE Investigators ${ }^{1}$ \\ ${ }^{a}$ Department of Neurology, University of Rochester Medical Center, Rochester, NY, USA \\ ${ }^{\mathrm{b}}$ Department of Neurology, Johns Hopkins University, Baltimore, MD, USA \\ ${ }^{\mathrm{c}}$ Departments of Psychiatry, Neurology, Neuroscience and Pharmacology, Johns Hopkins University, \\ Baltimore, MD, USA \\ ${ }^{\mathrm{d}}$ Department of Neurology, Massachusetts General Hospital and Harvard Medical School, Charlestown, MA, USA \\ ${ }^{\mathrm{e}}$ Department of Neurology, Georgetown University, Washington, D.C., USA \\ ${ }^{\mathrm{f}}$ Boston University School of Medicine, Boston, MA, USA
}

\begin{abstract}
We analyzed plasma $8 \mathrm{OHdG}$ concentrations in 20 individuals enrolled in the Pre-2CARE study before and after treatment with CoQ. Treatment resulted in a mean reduction in $8 \mathrm{OHdG}$ of $2.9 \pm 2.9 \mathrm{pg} / \mathrm{ml}$ for the cohort $(p=0.0003)$ and $3.0 \pm 2.6 \mathrm{pg} / \mathrm{ml}$, for the HD group $(p=0.002)$. Baseline $8 \mathrm{OHdG}$ levels were not different between individuals with HD and controls $(19.3 \pm 3.2 \mathrm{pg} / \mathrm{ml}$ vs. $19.5 \pm 4.7 \mathrm{pg} / \mathrm{ml}, p=0.87)$ though baseline CoQ levels were elevated in HD compared with controls $(p<0.001)$. CoQ treatment reduces plasma $80 \mathrm{HdG}$ and this reduction may serve as a marker of pharmacologic activity of $\mathrm{CoQ}$ in $\mathrm{HD}$.
\end{abstract}

Keywords: Huntington disease, coenzyme Q10, 8OHdG, oxidative injury

\section{INTRODUCTION}

Huntington Disease (HD) is an autosomal dominant neurodegenerative disease caused by the cytosineadenine-guanine (CAG) trinucleotide repeat expansion on chromosome 4 [1] and is characterized clinically by movement disorder, behavioral disturbances and dementia. Growing evidence implicates mitochondrial

\footnotetext{
${ }^{1}$ See Appendix for full listing of Pre-2CARE Investigators.

*Correspondence to: Kevin M. Biglan, MD, MPH, Associate Professor, Department of Neurology, University of Rochester, 1351 Mt. Hope Ave, Suite 223, Rochester, NY 14620, USA. Tel.: +1 585275 2427; Fax: +1 585276 1870; E-mail: Kevin_biglan@urmc.rochester.edu.
}

dysfunction and oxidative injury in the pathophysiology of HD [2].

Serum 8-hydroxy-2'-deoxyguanosine (8OHdG) is a marker of oxidative damage to DNA. It has been shown to be elevated in individuals with HD, ALS and Friedreich's Ataxia [3-5]. Hersch et al. have shown that this $8 \mathrm{OHdG}$ elevation in $\mathrm{HD}$ can be reduced by treatment with creatine [3]. CoQ exerts antioxidant properties in the mitochondrial electron transport chain and decreases $80 \mathrm{HdG}$ levels in a dose-dependent fashion in the R6/2 transgenic mouse model of HD [6]. However, the relationship between $\mathrm{CoQ}$ dosing and $8 \mathrm{OHdG}$ levels in humans is not known. 
We completed a secondary analysis of $8 \mathrm{OHdG}$ levels and response to CoQ treatment in 20 participants from the Pre-2CARE study.

\section{MATERIALS AND METHODS}

\section{Overview of Pre-2CARE}

The design and methods for Pre-2Care have been previously described [7]. Twenty individuals with HD and 8 healthy controls consented to a 20 -week openlabel, dose-escalation, safety and tolerability trial of CoQ. Participants started on $1200 \mathrm{mg} /$ day of CoQ, titrated to $3600 \mathrm{mg} /$ day at week 8 and followed for an additional 12 weeks. Venous sampling for CoQ levels at baseline and weeks 4, 8, 12 and 20 .

\section{Participants}

Twenty out of the 28 individuals enrolled in Pre2CARE (14 HD/6 Healthy Controls) had a sufficient amount of stored plasma samples available from baseline and 20 weeks and were thus included in this analysis.

\section{CoQ analysis}

Trough-level assays for CoQ plasma levels were performed for the primary Pre-2CARE analysis using techniques previously described [8].

\section{OHdG analysis}

Pre2-Care plasma samples were stored in a minus 80 degree freezer at the University of Rochester. Samples were shipped to the Matson laboratory and processed using a standard solid-phase extraction (SPE) protocol. A carbon column switching system, blindly assayed with a duplicate, was then used for measurements of 8OHdG [9].

\section{Statistical analyses}

Baseline and change in plasma $8 \mathrm{OHdG}$ and $\mathrm{CoQ}$ levels were compared between HD and healthy controls and between individuals with HD taking CoQ and those not taking CoQ at baseline using Wilcoxon two-sample exact tests. Wilcoxon one-sample tests evaluated the within-subject change from baseline to 20 weeks in 8OHDG levels and CoQ levels. The relationship between baseline and 20 week changes in plasma 8OHDG and CoQ levels were evaluated using Pearson's correlations. All tests were 2-sided at the 5\% significance level.

\section{RESULTS}

\section{Baseline characteristics}

Baseline characteristics of individuals with HD and healthy controls are detailed in Table 1. HD participants were generally early disease with 5 in Stage I, 8 in Stage II and one in Stage III. Four individuals in the HD group reported taking CoQ at baseline.

\section{CoQ levels}

Baseline mean (SD) CoQ levels (Table 1) were elevated in individuals with $\mathrm{HD}$ as compared with healthy controls, $1.65(1.13) \mathrm{mcg} / \mathrm{ml}$ vs. $0.74(0.26) \mathrm{mcg} / \mathrm{ml}$, $p=0.02$. CoQ levels were higher in individuals with HD who reported taking CoQ at baseline compared with those who did not, $2.8(1.2)$ vs. $1.2(0.77) \mathrm{mcg} / \mathrm{ml}$, $p=0.02$. However, baseline CoQ levels remained higher in individuals with HD compared with healthy controls even when those individuals taking $\mathrm{CoQ}$ at baseline were excluded, $1.6(1.5) \mathrm{mcg} / \mathrm{ml}$ vs. 0.74 (0.26) $\mathrm{mcg} / \mathrm{ml}, p<0.001$. CoQ levels increased at the final visit by a mean (SD) of $4.47(3.50) \mathrm{mcg} / \mathrm{ml}$ in the HD group compared with $3.52(2.06) \mathrm{mcg} / \mathrm{ml}$ in healthy controls $(p=0.66)$.

Table 1

Baseline characteristics

\begin{tabular}{|c|c|c|c|c|c|}
\hline \multirow[t]{2}{*}{$\begin{array}{l}\text { Characteristics } \\
\text { Gender (female/male) }\end{array}$} & \multicolumn{2}{|c|}{$\begin{array}{l}\text { Manifest HD } \\
\quad(n=14) \\
(8 / 6)\end{array}$} & \multicolumn{2}{|c|}{$\begin{array}{c}\text { Healthy } \\
\text { Controls }(n=6) \\
(4 / 2)\end{array}$} & \multirow[t]{2}{*}{$\begin{array}{c}P \text {-value } \\
1.00\end{array}$} \\
\hline & Mean (SD) & $\overline{\text { Median (range) }}$ & Mean (SD) & $\overline{\text { Median (range) }}$ & \\
\hline Age & $52.65(8.61)$ & $50.35(26.64)$ & $51.57(8.64)$ & $47.52(22.90)$ & 0.72 \\
\hline UHDRS motor (mean $\pm \mathrm{sd})$ & $43.71(12.63)$ & $43.50(41.00)$ & N/A & N/A & N/A \\
\hline $\mathrm{TFC}($ mean $\pm \mathrm{sd})$ & $9.64(1.86)$ & $9.50(6.00)$ & N/A & N/A & N/A \\
\hline Baseline plasma CoQ (mcg/ml) & $1.65(1.13)$ & $1.21(3.73)$ & $0.74(0.26)$ & $0.68(0.66)$ & 0.02 \\
\hline Baseline plasma $80 \mathrm{OdG}(\mathrm{pg} / \mathrm{ml})$ & $18.98(3.26)$ & $18.70(12.00)$ & $19.57(5.47)$ & $17.70(14.70)$ & 0.97 \\
\hline
\end{tabular}

$\mathrm{HD}=$ Huntington Disease; UHDRS = Unified Huntington Disease Rating Scale; TFC = Total Functional Capacity; CoQ = Coenzyme $\mathrm{Q} 10 ; 8 \mathrm{OHdG}=8$-hydroxy-2'-deoxyguanosine; $\mathrm{SD}=$ standard deviations; N/A = not applicable. 


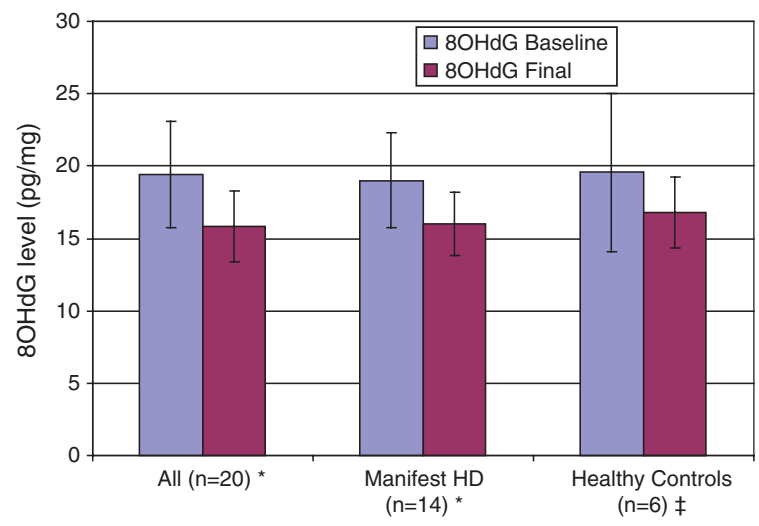

Fig. 1. 8OHdG levels at baseline and after 20 weeks of treatment with $\mathrm{CoQ}$ in manifest HD and healthy controls. For the change in $8 \mathrm{OHdG}$ from baseline: ${ }^{*} p<0.001,{ }^{\ddagger} p=0.79$. Error bars represent the SD of the mean $8 \mathrm{OHdG}$ level.

\section{$80 H d G$ levels}

Baseline mean (SD) $80 \mathrm{OHd}$ levels were not significantly different between HD and healthy controls, 18.98 (3.28) pg/ml vs. 19.57 (5.47) pg/ml, $p=0.97$. There was no difference in baseline $80 \mathrm{OHG}$ levels between the HD participants who reported taking CoQ at baseline and those who did not, 19.6 (3.2) $\mathrm{pg} / \mathrm{ml}$ vs. 18.8 (3.4) $\mathrm{pg} / \mathrm{ml}, p=0.45$. Administration of CoQ led to a mean (SD) reduction in $8 \mathrm{OHdG}$ of $2.9(2.9) \mathrm{pg} / \mathrm{ml}$ for the entire cohort, $p=0.0003$, and $3.0(2.6) \mathrm{pg} / \mathrm{ml}$, for the HD group, $p=0.002$. Healthy controls had a reduction in $80 \mathrm{OHdG}$ of $2.8(4.0) \mathrm{pg} / \mathrm{ml}, p=0.15$. Figure 1 shows the baseline and final $80 \mathrm{HdG}$ levels by group.

\section{DISCUSSION}

In this study, CoQ administration reduced plasma $8 \mathrm{OHdG}$ levels in individuals with HD. These findings are consistent with data showing a reduction in $8 \mathrm{OHdG}$ in the R6/2 mouse model treated with CoQ [6] and in HD individuals treated with creatine, a cytoplasmic antioxidant [3]. While not significant, we found a similar reduction in $8 \mathrm{OHdG}$ in healthy controls treated with CoQ, suggesting the effect of $\mathrm{CoQ}$ on $8 \mathrm{OHdG}$ may be non-specific. Together these results suggest that $8 \mathrm{OHdG}$ may serve as a biomarker of the pharmacological activity of CoQ in HD.

A leading hypothesis of HD pathophysiology is that mitochondrial dysfunction leads to increased oxidative stress [2]. $8 \mathrm{OHdG}$ is a marker of oxidative injury to DNA. Increases in $8 \mathrm{OHdG}$ have been found in postmortem HD brain tissue, [10] in the R6/2 mouse model [6], and in other neurodegenerative diseases where oxidative injury is important [4].

CoQ has demonstrated neuroprotective properties in experimental models of HD [11] and may slow progression in patients with HD [12] and Parkinson disease, [13] through stabilization of the mitochondrial membrane, improving ATP production, and as an antioxidant [14]. Our study supports the hypothesis that $\mathrm{CoQ}$ may reduce oxidative injury in $\mathrm{HD}$ as measured by $8 \mathrm{OHdG}$.

These findings have potential implications for disease modifying therapies in HD. While the current data are insufficient to address the validity of $8 \mathrm{OHdG}$ as a surrogate marker of clinical effectiveness, identifying $8 \mathrm{OHdG}$ as a marker of the pharmacological activity of an intervention is a critical step in validating $8 \mathrm{OHdG}$ as a potential surrogate marker [15]. In addition, ongoing Huntington Study Group trials of $\mathrm{CoQ}$ and Creatine in manifest HD (2CARE, NCT00608881; CREST-E, NCT00712426) and pre-manifest HD (PREQUEL, NCT00920699), as well as the Prospective Huntington At-Risk Observational Study (PHAROS) [16] will provide additional information on the effectiveness of CoQ and the utility of $8 \mathrm{OHdG}$ as a pharmacological activity and natural history biomarker in HD.

In contrast to previous studies [3] we found no difference in plasma $8 \mathrm{OHdG}$ levels comparing individuals with HD and healthy controls. Plasma $8 \mathrm{OHdG}$ levels in participants with HD were in the range previously reported for healthy controls and were less than half the levels reported for HD [3]. A plausible explanation is the elevated baseline CoQ levels in our HD group. While this is partially accounted for by the fact that four participants reported taking CoQ at baseline, CoQ levels remained higher in the HD group even when those participants were excluded. Perhaps individuals with $\mathrm{HD}$ have naturally high levels of CoQ; however, in a study of CoQ and remacemide in HD (CARE-HD) mean (SD) baseline CoQ levels were $0.81(0.28) \mathrm{mcg} / \mathrm{ml}$, much lower than the HD participants and similar to the healthy controls in this study (K. Kieburtz, personal communication, [12]). Alternatively, some HD subjects may have been taking CoQ and either did not report CoQ use or had recently discontinued it, as CoQ levels can remain elevated for weeks following discontinuation of CoQ [17]. The duration of this effect on $8 \mathrm{OHdG}$ is not known. Other potential explanations include laboratory error, differences in sampling and storage, or that our findings simply reflect the normal distribution of $8 \mathrm{OHdG}$ in 
this population. Future and ongoing research exploring $8 \mathrm{OHdG}$ in HD may clarify this issue.

This study has several limitations. The small sample size may account for our findings of no difference in $8 \mathrm{OHdG}$ between HD and healthy controls. However, despite the sample size, we found reduction in $8 \mathrm{OHdG}$ with CoQ and differences in baseline CoQ between groups. Also, $8 \mathrm{OHdG}$ levels in our study are comparable to levels reported in healthy controls and are lower than reported in HD [3]. Prior CoQ use was not excluded or systematically evaluated, which may have influenced the results. Finally, the relationship of $8 \mathrm{OHdG}$ to disease stage and progression in $\mathrm{HD}$ remains unclear and requires further study.

The current study demonstrates that plasma $80 \mathrm{HdG}$ is reduced with $\mathrm{CoQ}$ treatment and therefore may serve as a useful biomarker in HD to screen compounds with putative antioxidant mechanisms. We did not confirm previous reports of elevated $8 \mathrm{OHdG}$ in manifest $\mathrm{HD}$ though this may be secondary to concurrent CoQ use in our HD participants. Future studies need to ensure that participants do not have significant prior antioxidant exposure at baseline. Ongoing observational studies and clinical trials of CoQ and creatine in HD will refine our understanding of $8 \mathrm{OHdG}$ as a biomarker in HD.

\section{ACKNOWLEDGMENTS}

The authors would like to thank Matt Grana and Michael Bull for assistance in the preparation of this manuscript. The original Pre-2Care study was performed with funding from the CHDI/HiQ foundation.

This study was partially supported by NIH grants NS16375 (C.A. Ross) and NS058793 (S. Hersch).

\section{Huntington study group Pre-2Care investigators}

Steering Committee: University of Western Ontario: H. Christopher Hyson, MD (Medical Monitor). University of Rochester, Rochester, NY: Karl Kieburtz, MD, MPH (Principal Investigator); Ira Shoulson, MD; Michael McDermott, PhD (Chief Biostatistician); Bernard Ravina, MD; Elisabeth A. de Blieck, MPA CRCC (Project Coordinator). Massachusetts General Hospital, Charlestown, MA: Merit E. Cudkowicz, MD, MSc (Co-Principal Investigator). Boston University School of Medicine, Boston, MA and the Edith Nourse Rogers Veterans Administration Hospital, Bedford, MA: Robert J. Ferrante, MSc, PhD.

Site Investigators and Coordinators: University of Rochester Medical Center, Rochester, NY: Peter
Como, PhD; Sam Frank, MD; Carol Zimmerman, RN. Massachusetts General Hospital, Charlestown, MA: Merit E. Cudkowicz, MD, MSc; Kimberly Ferrante; Kristyn Newhall, BS. Institute for Neurodegenerative Disorders, New Haven, CT: Danna Jennings, MD; Tammie Kelsey, LPN. Wake Forest University School of Medicine, Winston-Salem, NC: Francis Walker, MD; Vicki Hunt, RN.

Biostatistics and Clinical Trial Coordination Center: University of Rochester, Rochester, NY: Susan Daigneault (Data Control Clerk); Michele Goldstein, BS (Information Analyst); Joseph Weber, BS (Database Manager); Arthur Watts, BS (Biostatistics Programmer).

Laboratory Support: Weill Medical College of Cornell University, New York, NY: M. Flint Beal, MD; Susan E. Browne, PhD; Linda J. Metakis.

\section{REFERENCES}

[1] Huntington's Disease Collaborative Research Group. A novel gene containing a trinucleotide repeat that is expanded and unstable on Huntington's disease chromosomes. Cell. 1993;72:971-83.

[2] Koroshetz WJ, Jenkins BG, Rosen BR, Beal MF. Energy metabolism defects in Huntington's disease and effects of coenzyme Q10. Ann Neurol. 1997;41:160-5.

[3] Hersch SM, Gevorkian S, Marder K, et al. Creatine in Huntington disease is safe, tolerable, bioavailable in brain and reduces serum $8 \mathrm{OH} 2$ 'dG. Neurology. 2006;66:250-2.

[4] Bogdanov M, Brown RH, Matson W, et al. Increased oxidative damage to DNA in ALS patients. Free Radic Biol Med. 2000;29:652-8.

[5] Schulz JB, Dehmer T, Schols L, et al. Oxidative stress in patients with Friedreich ataxia. Neurology. 2000;55: 1719-21.

[6] Smith KM, Matson S, Matson WR, et al. Dose ranging and efficacy study of high-dose coenzyme Q10 formulations in Huntington's disease mice. Biochim Biophys Acta. 2006; 1762:616-26.

[7] The Huntington Study Group Pre-2CARE Investigators. Safety and tolerability of high dosage coenzyme Q10 in Huntington's disease and healthy subjects. Movement Disorders 2010;25:1924-8.

[8] Shults CW, Haas RH, Passov D, Beal MF. Coenzyme Q10 levels correlate with the activities of complexes I and II/III in mitochondria from parkinsonian and nonparkinsonian subjects. Ann Neurol. 1997;42:261-4.

[9] Bogdanov MB, Acworth IN, ed. The Use of HPLC/EC for Measurements of Oxidative DNA Damage: World Scientific; 2003.

[10] Polidori MC, Mecocci P, Browne SE, Senin U, Beal MF. Oxidative damage to mitochondrial DNA in Huntington's disease parietal cortex. Neurosci Lett. 1999;272:53-6.

[11] Ferrante RJ, Andreassen OA, Dedeoglu A, et al. Therapeutic effects of coenzyme Q10 and remacemide in transgenic mouse models of Huntington's disease. J Neurosci. 2002;22: 1592-9. 
[12] A randomized, placebo-controlled trial of coenzyme Q10 and remacemide in Huntington's disease. Neurology. 2001;57:397-404.

[13] Shults CW, Oakes D, Kieburtz K, et al. Effects of coenzyme Q10 in early Parkinson disease: Evidence of slowing of the functional decline. Arch Neurol. 2002;59:1541-50.

[14] Pepping J. Coenzyme Q10. Am J Health Syst Pharm. 1999;56:519-21.

[15] Mildvan D, Landay A, De Gruttola V, Machado SG, Kagan J. An approach to the validation of markers for use in AIDS clinical trials. Clin Infect Dis. 1997;24:764-74.
[16] At risk for Huntington disease: The PHAROS (Prospective Huntington At Risk Observational Study) cohort enrolled. Arch Neurol. 2006;63:991-6.

[17] Hosoe K, Kitano M, Kishida H, Kubo H, Fujii K, Kitahara M. Study on safety and bioavailability of ubiquinol (Kaneka $\mathrm{QH})$ after single and 4-week multiple oral administration to healthy volunteers. Regul Toxicol Pharmacol. 2007;47: 19-28. 